\title{
Social and International Relations of Science
}

$\mathrm{T}$ HE growing feeling among scientific workers that they have a definite part to play in the promotion of social well-being and in international affairs found expression in a discussion in NATURE of April 23. The outcome was a suggestion that the British Association should take up the matter, and the Council of the Association put forward a proposal for the establishment of a new Division for the Social and International Relations of Science. The proposal was agreed to by a meeting at Cambridge of the General Committee on August 17. We print below the memorandum prepared for the General Committee.

At the present time a strong feeling exists that the social relations of science demand close and objective study. The question has been dealt with recently in the Press and elsewhere. At an informal meeting of persons specially interested, it was stated that there is nothing in the constitution of the British Association to prevent the establishment of machinery within that organization for the purpose desired. A resolution was thereupon addressed from this meeting to the Council of the Association, inviting the Association to establish a special department which would consider the social and international relations of science, by means of inquiry, publication, and the holding of meetings not necessarily confined to the annual meetings of the Association.

International relations were specified in this resolution primarily because of the deep interest of the American Association for the Advancement of Science in the subject. Discussion is expected to take place between officers of the two Associations, during the present summer, on the best means for international co-operation.

The Council supported the proposal to establish an organization for these purposes within the Association. They appointed a Committee to formulate a scheme for the working of such an organization, to be presented to the General Committee at the Cambridge Meeting. It is thought that the organization should work on lines in some respects different from those of a Section, and should not bear that title. The term 'Division' is therefore recommended.

The purpose of the Division would be to further the objective study of the social relations of science. The problems with which it would deal would be concerned with the effects of advances in science on the well-being of the community, and, reciprocally, the effects of social conditions upon advances in science.

The Division would be worked by a Committee, nominated annually by the Council and appointed by the General Committee. The Council should have power to appoint additional members of the Committee during the year.

The Committee should embody the existing British Science Guild Committee of the Association, inasmuch as the Norman Lockyer, Alexander Pedler, and Radford Mather Lectures, now administered by that Committee, would appropriately come within the purview of the Division.

The President of the Association and the General Officers should be ex-officio members of the Committee. A chairman of the Committee should be appointed for a fixed period of office. A fixed proportion of the ordinary members of the Committee should retire annually (as in the case of the Council) and should not be eligible for immediate re-election.

The functions of the Committee would be :

(a) To arrange meetings of the Division both at the time and place of the Annual Meetings of the Association, and elsewhere at other times, as invited or otherwise arranged ; to appoint speakers and to accept or reject communications offered to the Division.

(b) To furnish nuaterial for the information of the public.

(c) To co-ordinate work dealing with the social relations of science, both at home and abroad.

(d) To be prepared to act in a consultative capacity and to supply information, and to that end to establish relations with organizations and persons engaged in practical administration.

(For the furtherance of the above objects, the Committee, immediately upon the establishment of the Division, should issue an announcement thereof, together with a reasoned statement of its aims, to institutions and other organizations and individuals known or likely to be interested in its work.)

(e) To set up sub-committees for executive purposes, or for research, inquiry, or co-ordination. If any such sub-committee should require a grant of money for its work, the Committee should be empowered to apply for such grant to the General Committee or the Council in accordance with the usual procedure relating to research committees.

$(f)$ To maintain close relations with the Sections of the Association and their Organizing 
Committees. In particular, there may be imagined subjects which two or more Sections might be disposed to recommend to the Division for discussion, in lieu of arranging joint meetings of the Sections. The Committee of the Division, on its part, should be enabled to invite the advice of the sectional organizations on all appropriate questions. The Organizing Sectional Committees should be kept regularly informed of the activities of the Division.
The Committee should meet regularly throughout the year, at intervals determined by itself, and in particular it should hold a meeting at or near the time of the joint meetings of Organizing Sectional Committees in January, in order to assure the relations with the Sections referred to above.

The Committee should report to the Council as and when necessary, and annually through the Council to the General Committee.

\title{
Logic and Probability in Physics*
}

\author{
By Dr. C. G. Darwin, F.R.S.
}

$\mathrm{I}^{\mathrm{N}}$ choosing a theme for my address I was in some difficulty. The main subjects of present interest in physics, the nucleus of the atom, cosmic rays, and the phenomena at deep temperatures, are being dealt with in the discussions of our Section, so that they would be excluded even apart from the fact that I cannot speak on them with authority. It would have been possible for me to choose a narrower subject, but I could not feel that this would have possessed the general interest that such an occasion demands, and so with some trepidation I am venturing on an even wider theme and am going to touch on the philosophy of our subject. This is a dangerous thing to do for one who has never made more than the most superficial study of pure philosophy, but still I do not apologize for it, because it appears to me that recent scientific history has revealed a deep schism between the professional philosophers and the scientists, and this schism is worthy of examination.

General philosophy claims to be the critical subject which lays down for all of us what we may be allowed to think, and yet it has played no part whatever in the great revolutions of human thought of the present century-those connected with relativity and the quantum theory. It might have been expected that the scientists would have been constantly consulting the philosophers as to the legitimacy of their various speculations, but nothing of the kind has happened. Since no one can dispense with some sort of metaphysic, each scientist has made one for himself, and no doubt they contain many crudities, but it would seem that a deep interest in metaphysic is a disadvantage rather than an advantage to the physicist-at least I have the impression that those of my friends who are most inclined to

- From the presidential address to Section A (Mathematical and Physical Sciences) of the British Association, delivered at Cambridge on August 19. speculate on the ultimate things appear to be the ones whose scientific work is most hampered by doing so. Now I propose to risk a similar indiscretion. I want to embody in it the practical philosophy of a physicist, and I do not mean it as an attack on the pure philosophers, who are very reasonable people, only chargeable with the minor offence of not having made me want to read their books!

I had better begin by stating shortly the ideas I intend to discuss. There is a notable contrast between the way we think about things and the way we think we ought to think about them. We have set up as an ideal form of reasoning the formal logic which has held the field since the days of Aristotle. We rarely conform to this ideal, but instead we usually make use of arguments having no accurate axiomatic basis, which compel belief because of some large accumulation of favourable evidence. I intend to develop the idea that the old logic was devised for a world that was thought to have hard outlines, and that, now that the new mechanics has shown that the outlines are not hard, the method of reasoning must be changed. The key to the modification has already long been in our hands in the principle of probability, but whereas in the past constant attempts were made to fit this into the old system, the new mechanics suggests the possibility of a different synthesis. Though I hope this subject will be found interesting in itself, I would not have ventured to bring it forward if $I$ had not also a very practical purpose in doing so, and that is to urge that our mathematical education both at school and university has been gravely deficient in that it has put all the emphasis on matters susceptible of rigorous proof, while it has very completely neglected the equally important subjects of statistics and probability. I shall enter into these matters at the end of my address. 